\title{
Zr-MCM-41 Nanoreactors as Efficient and Reusable Catalysts in the Synthesis of New Aminonitriles by the Strecker Reaction
}

\author{
Zohreh DERIKVAND $^{\mathrm{a}}$, Fatemeh DERIKVAND ${ }^{\mathrm{b}}$ \\ Department of Chemistry, Faculty of Science, Islamic Azad University, Khorramabad Branch, Khorramabad, Iran
}

\begin{abstract}
The synthesis and characterization of Zr-MCM-41 nanoreactors and their catalytic activity in the synthesis of new amino nitrile derivatives by the Strecker reaction in high yields and in short reaction times is reported.
\end{abstract}

Key words: Zr-MCM-41; Strecker reaction; aminonitrile; three component one-pot reaction

CLC number: O643

Document code: A

Received 1 November 2010. Accepted 15 December 2010.

${ }^{a}$ Corresponding author.Tel/Fax: +98-661-6200399; E-mail: zderik@yahoo.com

${ }^{b}$ Corresponding author.Tel/Fax: +98-661-6200399; E-mail:f_derikvand@yahoo.com

English edition available online at Elsevier ScienceDirect (http://www.sciencedirect.com/science/journal/18722067).

The three-component condensation of aldehydes, amines, and trimethylsilyl cyanide (TMSCN) in the Strecker reaction is an important reaction in organic synthesis. The products are $\alpha$-aminonitrile derivatives, which are versatile intermediates that can be transformed into a variety of building blocks such as $\alpha$-amino acids, 1,2-diamines, and nitrogen-containing heterocycles [1]. A variety of acid catalysts have been used in this reaction [2-8]. The tedious work-up procedure, long reaction time, toxic catalysts, and the use of an inert atmosphere are some of the drawbacks of these methods. For example, Al-MCM-41 has been used under an argon atmosphere [8].

New green legislation requires a decrease in waste creation and the use of more environmentally friendly alternative catalysts, which makes the current homogeneous organic reactions environmentally unacceptable [9].

Considerable attention has been given to M41S (Mobil Composition of Matter) mesoporous materials but particularly the MCM-41 family because of their unique properties [10-12]. They have high specific surface areas, high pore volumes, and tunable pore sizes with a narrow distribution. However, Si-based MCM-41 exhibits only mild acidity, which is much weaker than that of the microporous zeolites [13]. The incorporation of zirconium into the MCM-41 framework increases both the Lewis and Brönsted acidity [13].

Herein, we report a new approach toward the synthesis of Zr-MCM-41, its characterization, and its catalytic activity in a three-component one-pot synthesis of $\alpha$-aminonitrile derivatives by condensing aldehydes, amines, and trimethylsilyl cyanide.

\section{Experimental}

\subsection{Preparation of Zr-MCM-41}

Fumed silica $(8 \mathrm{~g})$ was added to a solution of sodium hydroxide $(2 \mathrm{~g})$ in distilled water $(150 \mathrm{ml})$ in a baker at $80^{\circ} \mathrm{C}$. The resulting mixture was continuously stirred until a clear solution was obtained. Cethyltrimethyl ammonium bromide (CTAB, $3 \mathrm{~g}$ ) was slowly added to this solution under vigorous stirring at room temperature. The resulting gel was stirred for an additional $2 \mathrm{~h}$. In the next stage zirconium (IV) oxide chloride octahydrate (5 g) was dissolved in distilled water $(100 \mathrm{ml})$ by adding concentrated $\mathrm{H}_{2} \mathrm{SO}_{4}(2.5 \mathrm{ml})$ until a clear solution was obtained. This solution was added to the resulting gel in a dropwise manner over $2 \mathrm{~h}$ under vigorous stirring. The obtained gel was transferred into a Teflon-lined stainless steel autoclave for hydrothermal treatment at $100{ }^{\circ} \mathrm{C}$ over $3 \mathrm{~d}$. The resulting solid product was recovered after filtration and washing several times with deionized water. The obtained white solid was dried in air at $100^{\circ} \mathrm{C}$ for $5 \mathrm{~h}$. Finally, the sample was calcined at 600 ${ }^{\circ} \mathrm{C}$ for $16 \mathrm{~h}$ in air. The heating rate was $1.5^{\circ} \mathrm{C} / \mathrm{min}$ and the molar ratio of $\mathrm{Si} / \mathrm{Zr}$ was 8 .

\subsection{Characterization of $\mathrm{Zr}-\mathrm{MCM}-41$}

$\mathrm{X}$-ray diffraction (XRD) patterns were obtained using a Siefert 3003 PTS diffractometer with $\mathrm{Cu} K_{\alpha}$ radiation $(\lambda=$ $0.15406 \mathrm{~nm}$ ). Fourier transform infrared (FT-IR) spectra were recorded using a Bruker Tensor 27 IR spectrometer and $\mathrm{KBr}$ pellets in a range of $400-4000 \mathrm{~cm}^{-1}$ under atmos- 
pheric conditions. Scanning electron micrographs (SEM) were obtained on a Holand Philips XL-30 microscope with an accelerating voltage of $25 \mathrm{kV}$. The sample was deposited on a sample holder with an adhesive carbon foil and sputtered with gold. Nitrogen adsorption studies were performed at liquid nitrogen temperature using a BELSORP-miniII.

\subsection{Synthesis of $\alpha$-aminonitrile derivatives}

All solvents and reagents were purchased from Aldrich and Merck and were of high-grade quality, and used without any purification.

In a general procedure, a solution of an aromatic aldehyde $(1 \mathrm{mmol})$, a primary amine $(1.2 \mathrm{mmol}), \mathrm{TMSCN}$ (1 $\mathrm{mmol})$, and $\mathrm{Zr}-\mathrm{MCM}-41$ (0.03 g) in $\mathrm{CH}_{3} \mathrm{CN}$ (5 ml) was stirred under reflux conditions for an appropriate time. After reaction completion (monitored by TLC) the catalyst, which is not soluble in boiling acetonitrile, was easily filtered off and the mixture was cooled to room temperature. The solid products were collected by filtration, washing with water and aqueous ethanol, and purified by recrystallization from ethanol. For the oily products the reaction mixture was poured into distilled water $(15 \mathrm{ml})$ and the product was extracted with chloroform $(20 \mathrm{ml} \times 2)$ and dried over $\mathrm{MgSO}_{4}$. The solvent was removed under reduced pressure and crude product was purified by column chromatography over silica gel (hexane- $\mathrm{Et}_{2} \mathrm{O}$ ). Compounds 1,2 , and 3 are new products (Scheme 1) and the other products are known compounds, and their physical and spectroscopic data have been reported in the literature. Melting points were measured using the capillary tube method with an electrothermal 9200 apparatus. ${ }^{1} \mathrm{H}$ NMR spectra were recorded on a Bruker AQS AVANCE-300 MHz or a $500 \mathrm{MHz}$ spectrometer using TMS as an internal standard $\left(\mathrm{CDCl}_{3}\right.$ or DMSO- $\mathrm{d}_{6}$ solution).

Compound 1: 2,2'-(1,4-phenylene)bis(2-(4-methylbenzylamino)acetonitrile). ${ }^{1} \mathrm{H} \mathrm{NMR}\left(300 \mathrm{MHz}, \mathrm{CDCl}_{3}\right): \delta 1.86$ $(2 \mathrm{H}$, br. s, $2 \mathrm{NH}), 2.03(6 \mathrm{H}, \mathrm{s}, 2 \mathrm{Me}), 3.86\left(4 \mathrm{H}, \mathrm{s}, 2 \mathrm{CH}_{2}\right)$, $6.92\left(4 \mathrm{H}, \mathrm{d}, J=9 \mathrm{~Hz}, 4 \mathrm{CH}_{\mathrm{Ar}}\right), 7.33(4 \mathrm{H}, \mathrm{d}, J=9 \mathrm{~Hz}$, $\left.4 \mathrm{CH}_{\mathrm{Ar}}\right), 7.60\left(4 \mathrm{H}, \mathrm{s}, 4 \mathrm{CH}_{\mathrm{Ar}}\right)$. Mass: 395.3, 373.4. Anal. Calcd (\%): C, 79.16; H, 6.64; N, 14.20; Found: C, 78.76; H, $6.44 ; \mathrm{N}, 14.50$.

Compound 2: 2-(4-chlorophenyl)-2-(4-morpholinophenylamino)acetonitrile. ${ }^{1} \mathrm{H}$ NMR $\left(300 \mathrm{MHz}, \mathrm{CDCl}_{3}\right): \delta$ 3.06-3.09 (4H, m, $\left.2 \mathrm{CH}_{2}\right), 3.85-3.88\left(4 \mathrm{H}, \mathrm{m}, 2 \mathrm{CH}_{2}\right), 5.36$
$(1 \mathrm{H}, \mathrm{d}, J=9, \mathrm{CH}), 6.77\left(2 \mathrm{H}, \mathrm{d}, J=9 \mathrm{~Hz}, 2 \mathrm{CH}_{\mathrm{Ar}}\right), 6.92(2 \mathrm{H}$, $\left.\mathrm{d}, J=9 \mathrm{~Hz}, 2 \mathrm{CH}_{\mathrm{Ar}}\right), 7.44\left(2 \mathrm{H}, \mathrm{d}, J=9 \mathrm{~Hz}, 2 \mathrm{CH}_{\mathrm{Ar}}\right), 7.57$ $\left(2 \mathrm{H}, \mathrm{d}, J=9 \mathrm{~Hz}, 2 \mathrm{CH}_{\mathrm{Ar}}\right)$.

Compound 3: 2-(2-(1H-imidazol-4-yl)ethylamino)-2(4-chlorophenyl)acetonitrile. ${ }^{1} \mathrm{H}$ NMR $\left(300 \mathrm{MHz} \mathrm{CDCl}_{3}\right): \delta$ $\left(2 \mathrm{H}, \mathrm{t}, J=6, \mathrm{CH}_{2}\right), 2.96-3.09\left(2 \mathrm{H}, \mathrm{m}, \mathrm{CH}_{2}\right), 4.81(1 \mathrm{H}, \mathrm{s}$, $\mathrm{CH}), 6.84\left(1 \mathrm{H}, \mathrm{s}, \mathrm{CH}_{\mathrm{Ar}}\right), 7.35-7.46\left(4 \mathrm{H}, \mathrm{m}, 4 \mathrm{CH}_{\mathrm{Ar}}\right), 7.56$ $\left(1 \mathrm{H}, \mathrm{s}, \mathrm{CH}_{\mathrm{Ar}}\right)$. Mass $(\mathrm{m} / \mathrm{z}): 260,254,234$. Anal. Calcd (\%): C, 59.89; H, 5.03; Cl, 13.60; N, 21.19; Found: C, 59.95; H, $5.13 ; \mathrm{N}, 21.19$.

\subsection{Recycling the catalyst}

The catalyst is not soluble in boiling acetonitrile and it was removed by hot filtration after reaction completion. In the synthesis of 2-(4-chlorophenyl)-2-(4-methylbenzylamino)acetonitrile the catalyst was recovered three times, washed with diethyl ether, and reused in a similar reaction.

\section{Results and discussion}

Mesoporous silicate materials contain a chemically inert silicate framework. To induce specific catalytic activity researchers have tried to incorporate a variety of metals into the mesostructure by either direct synthesis/ion-exchange or impregnation. Among the transition metals, zirconium is considered to be important because of the possible strong polarization of the $\mathrm{Si}-\mathrm{O}^{-\delta} \cdots \mathrm{Zr}^{+\delta}$ linkages [14].

The surface acidity of the mesoporous solids is significantly influenced by the incorporation of zirconium ions into the framework. The addition of zirconium creates Brönsted acid sites and also enhances the acid strength of both the Lewis and Brönsted acid sites. The diameter of $\mathrm{Zr}^{4+}$ is much larger than that of $\mathrm{Si}^{4+}$ and when smaller $\mathrm{Si}^{4+}$ ions are replaced by larger $\mathrm{Zr}^{4+}$ ions in the framework of the solid the bond length of $\mathrm{Zr}-\mathrm{O}-\mathrm{Si}$ clearly differs from that of $\mathrm{Si}-\mathrm{O}-\mathrm{Si}$. This must lead to the deformation of some structures and the generation of microstrain in the lattice cell [15]. This feature can be useful for reactions that require both types of acid sites.

\subsection{Characterization of the catalyst}

The FT-IR spectrum of the prepared Zr-MCM-41 is given
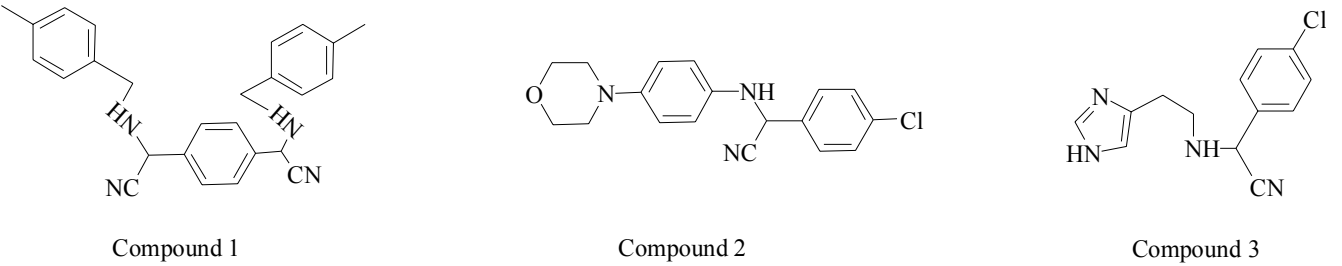

Scheme 1. Structure of compound 1,2, and 3 . 
in Fig. 1. The observed bands between 809 and $468 \mathrm{~cm}^{-1}$ are assigned to the symmetric stretching and bending vibrations of the $\mathrm{Si}-\mathrm{O}-\mathrm{Si}$ groups, respectively [16]. The stretching and bending vibration modes of $\mathrm{O}-\mathrm{H}$ in the $\mathrm{Si}-\mathrm{OH}$ groups are present at 3431 and $1631 \mathrm{~cm}^{-1}$, respectively.

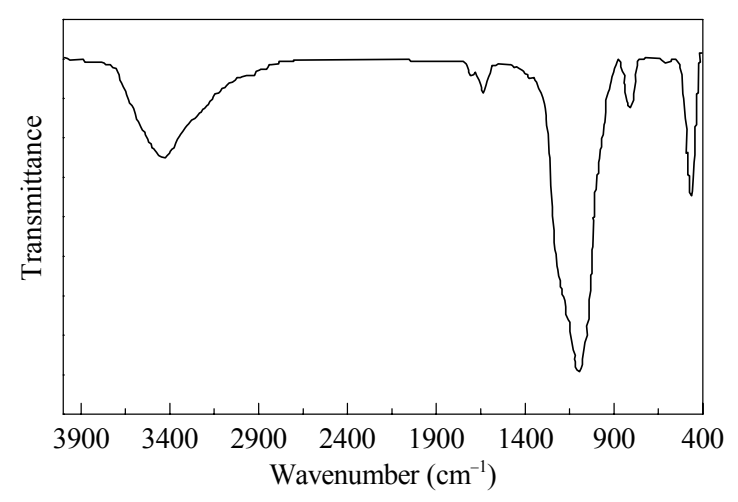

Fig. 1. FT-IR spectrum of the calcined Zr-MCM-41.

MCM-41 samples are typically characterized by an intense X-ray diffraction in the vicinity of $2 \theta=2^{\circ}$ and several other peaks in the $2 \theta$ range from $3^{\circ}$ to $8^{\circ}$ [17]. The XRD pattern of Zr-MCM-41 (Fig. 2) has a high-intensity (100) and two low-intensity reflections ((110) and (200)). These are characteristics of a hexagonal structure [18]. They exhibit long-range order and good textural uniformity of the mesoporous structure.

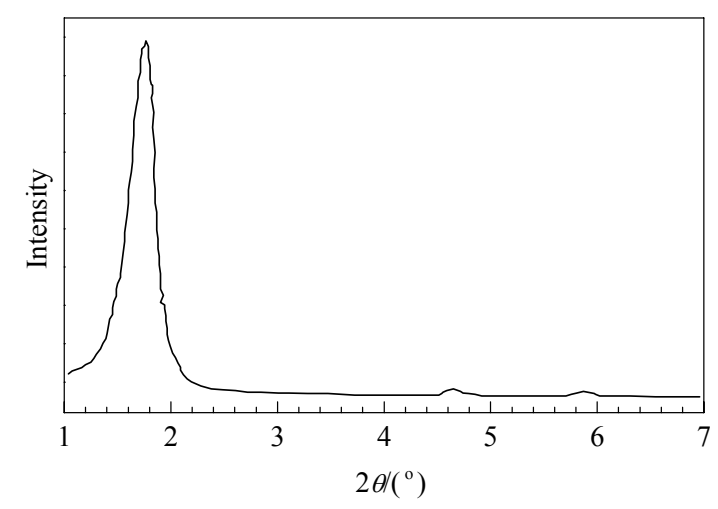

Fig. 2. XRD pattern of Zr-MCM-41.

The SEM image revealed that the synthesized Zr-MCM-41 particles are composed of irregular large particles (Fig. 3).

The specific surface area, pore volume, and average pore diameter of the Zr-MCM-41 was $676.2 \mathrm{~m}^{2} / \mathrm{g}, 1.2854 \mathrm{~cm}^{3} / \mathrm{g}$, and $2.06 \mathrm{~nm}$, respectively.

\subsection{Catalytic activity}

To study the catalytic activity of Zr-MCM-41, we initially studied the synthesis of 2-(4-chlorophenyl)-2-(4-methylben-

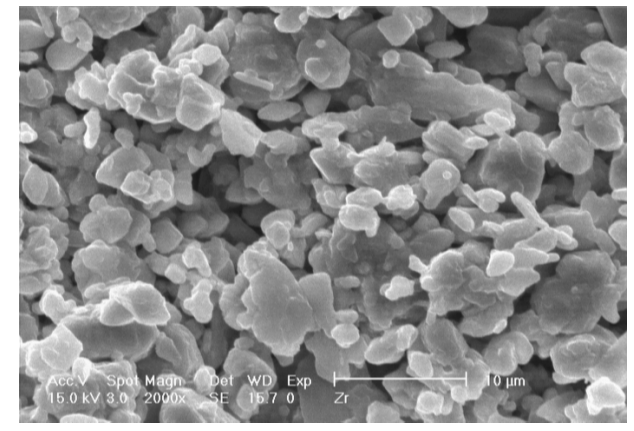

Fig. 3. SEM micrograph of the freshly activated Zr-MCM-41.

zylamino)acetonitrile by the condensation of 4-methylbenzylamine, 4-chlorobenzaldehyde, and TMSCN in different solvents under heating as a model reaction. As shown in Table 1 the best results were obtained in refluxing acetonitrile. We also determined the most efficient amount of catalyst required and the reaction temperature as well as the best results were obtained when using $0.03 \mathrm{~g}$ per $1 \mathrm{mmol}$ of starting material (Table 1). As shown in Table 1 this reaction is slower without the catalyst and after $20 \mathrm{~min}$ we obtained $45 \%$ of the product but the yield in the presence of $0.03 \mathrm{~g}$ of catalyst using the same time was $95 \%$.

Table 1 Synthesis of 2-(4-chlorophenyl)-2-(4-methylbenzylamino) acetonitrile in a 20 min reaction

\begin{tabular}{ccc}
\hline Solvent (temperature) & Catalyst loading $(\mathrm{g})$ & Yield $^{\mathrm{a}}(\%)$ \\
\hline EtOH (reflux) & 0.03 & 68 \\
$\mathrm{H}_{2} \mathrm{O}$ (reflux) & 0.03 & 70 \\
Solvent free $\left(80^{\circ} \mathrm{C}\right)$ & 0.03 & 40 \\
$\mathrm{CH}_{3} \mathrm{CN}$ (reflux) & 0.03 & 95 \\
$\mathrm{CH}_{3} \mathrm{CN}$ (reflux) & 0.05 & 95 \\
$\mathrm{CH}_{3} \mathrm{CN}$ (reflux) & 0.01 & 75 \\
$\mathrm{CH}_{3} \mathrm{CN}$ (reflux) & 0 & 45 \\
$\mathrm{CH}_{3} \mathrm{CN}$ (r.t) & 0.03 & 78 \\
\hline
\end{tabular}

${ }^{a}$ Yields are related to the isolated pure products.

This method was further employed to synthesize a variety of new or known amino nitrile derivatives. To show the general applicability of the method terephthaldehyde and a variety of benzaldehyde derivatives such as aldehydes, 4-morpholinoaniline, histamine, and benzylamine derivatives as an amine source were used in this reaction. The obtained results are summarized in Table 2. Separation and purification was very simple in these reactions. Zr-MCM-41 is not soluble in boiling acetonitrile but the products are soluble in boiling acetonitrile and the catalyst was separated by simple filtration. Most of the products are not soluble in the reaction media at room temperature and they were separated by filtration. For the oily products the reaction mixture was poured into distilled water and the product was extracted using chloroform and then the solvent was removed under reduce pressure. The crude products were purified by 
Table 2 Synthesis of $\alpha$-aminonitrile in the presence of a catalytic amount of Zr-MCM-41 under heating in acetonitrile

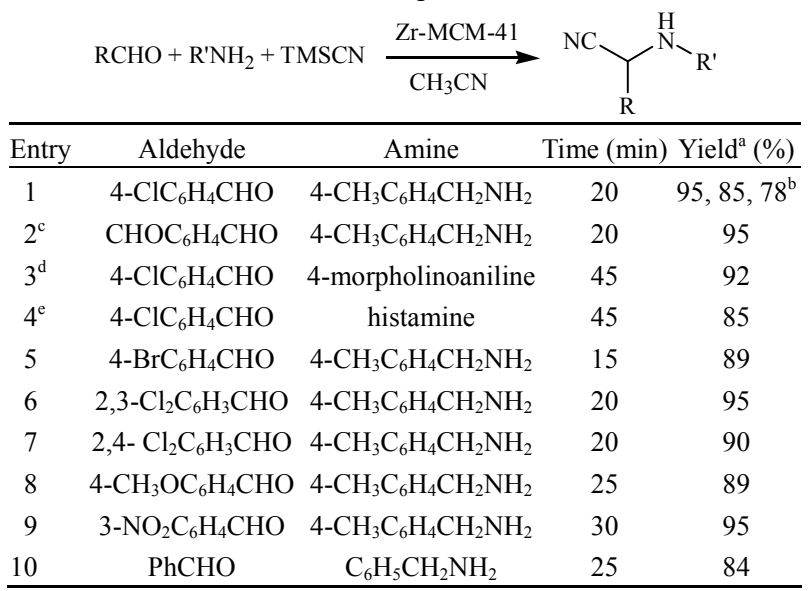

${ }^{a}$ Yields are related to isolated pure products. ${ }^{b}$ The catalyst was recycled and reused three times in the model reaction. ${ }^{\mathrm{c}}$ The product is compound $1 .{ }^{\mathrm{d}}$ The product is compound $2 .{ }^{\mathrm{e}}$ The product is compound 3 .

recrystallization from absolute EtOH or in some cases (oily products) by column chromatography over silica gel (hexane- $\mathrm{Et}_{2} \mathrm{O}$ ). For the new products, compounds 1, 2, and 3, the structure was determined by ${ }^{1} \mathrm{H}$ NMR and microanalysis. For the known compounds, which are all the other products in Table 2, their physical and spectroscopic data were compared with those of authentic samples and found to be identical [19]. In most cases the products were obtained in quantitative yield and we did not detect any cyanohydrin trimethylsilyl ethers as byproducts in this reaction.

It is noteworthy that the catalyst is recyclable and could be reused without a significant loss of activity. The catalyst was recycled and reused three times in the model reaction and the obtained results are summarized in Table 2, entry 1.

\section{Conclusions}

In summary, we report a simple and convenient procedure for the synthesis and characterization of Zr-MCM-41 nanoreactors. We used the synthesized nanoreactors as a green solid acid catalyst for the preparation of $\alpha$-amino ni- triles, which proceeded efficiently in acetonitrile under heating. The mild conditions and the use of a green, non toxic, inexpensive, and reusable catalyst in high yields and in relatively short reaction times are some of the advantages of this reaction.

\section{References}

1 Enders D, Shilvock J P. Chem Soc Rev, 2000, 29: 359

2 Paraskar A S, Sudalai A. Tetrahedron Lett, 2006, 47: 5759

3 De S K, Gibbs R A. Tetrahedron Let, 2004, 45: 7407

4 De S K. J Mol Catal A, 2005, 225: 169

5 Shen Z L, Ji S J, Loh T P. Tetrahedron, 2008, 64: 8159

6 Majhi A, Kim S S, Kadam S T. Tetrahedron, 2008, 64: 5509

7 Karimi B, Zareyee D. J Mater Chem, 2009, 19: 8665

8 Iwanami K, Seo H, Choi J C, Sakakura T, Yasuda H. Tetrahedron, 2010, 66: 1898

9 Clark J H, Rhodes C N. In: Clark J H Ed. Clean Synthesis Using Porous Inorganic Solid Catalysts and Supported Reagents. Cambridge: Royal Society of Chemistry, 2000

10 Beck J S, Vartuli J C, Roth W J, Leonowicz M E, Kresge C T, Schmidt K D, Chu C T W, Olson D H, Sheppard E W, McCullen S B, Higgins J B, Schlenker J L. J Am Chem Soc, 1992, 114: 10834

11 Eliche-Quesada D, Rodríguez-Castellón E, Jiménez-López A. Microporous Mesoporous Mater, 2007, 99: 268

12 Corma A. Chem Rev, 1997, 97: 2373

13 Chen L F, Noren L E, Wang J A, Zhou X L, Navarrete J, Hernandez I, Montoya A, Perez R P, Salas P, Castella P S. Catal Today, 2008, 133-135: 331

14 Eswaramoorthi I, Sundaramurthy V, Lingappan N. Microporous Mesoporous Mater, 2004, 71: 109

15 Chen L F, Noreňa L E, Navarrete J, Wang J A. Mater Chem Phys, 2006, 97: 236

16 Laughlin R B, Joannopoulos J D. Phys Rev B, 1977, 16: 2942

17 Liu X B, Sun H, Yang Y H. J Colloid Interface Sci, 2008, 319: 377

18 Behrens P, Stucky G D. Angew Chem, Int Ed, 1993, 32: 696

19 Oskooie H A, Heravi M M, Bakhtiari K, Zadsirjan V, Bamoharram F F. Synlett, 2006: 1768 and references cited therein 